\title{
Greenhouse Microclimate Flow Simulation: Influence of Inlet Flow Conditions
}

\author{
Syed Shabbar Raza, Khadije El Kadi, Isam Janajreh* \\ Mechanical Engineering Department, Khalifa University of Science and Technology, Masdar City, Abu Dhabi, UAE
}

\begin{abstract}
Greenhouse (GH) has been demonstrated as a profitable technology for food production with low demand of irrigation water. In this work, a numerical model is developed to study the micro-climatic environmental conditions inside a greenhouse distillation system for optimize operation. The system performance (temperatures, flow velocities, relative humidity) is presented and improvement factors for the system performance are suggested. The result shows that the inlet velocity and plant transpiration have a more pronounced effect on the relative humidity than the incoming temperature variation. As temperature increases by $8 \mathrm{C}^{\circ}$ the relative humidity decreases with few percentiles $(\sim 2 \%)$. When velocity varies between $0.2-0.7 \mathrm{~m} / \mathrm{s}$, and within the diurnal operation of the $\mathrm{GH}$, an increase of up to 5 points in the humidity is observed. Finally, when the transpiration increases from 0.2 to $1.2 \mathrm{~g} / \mathrm{m}^{3}$ the relative humidity observes a drastic jump of over 15 points.
\end{abstract}

Keywords: Sustainable Greenhouses, CFD, HVAC, Plant Transpiration

\section{Introduction}

Fresh water shortages and quality is becoming a pressing worldwide issue. Therefore, genuine effort must be made to lessen water depletion over the course of growing demand. Selfsufficient green house (GH) is a novel idea, and several studies incorporating solar stills have been presented in literature [1-5]. The main challenge remains to fundamentally understand and control the internal GH environment under either a hot or cold day while maintaining a healthy microclimate conditions for the growing plant inside it. This requires exhaustive experimental climatologically studies and due to the Multiphysics (thermal and two-phase flow and plants role) parametric interaction becomes unavoidable that preclude their setup accuracy. Alternatively, numerical flow simulation can be pursued methodologically to evaluate temperature, humidity, and flow distribution, following extensive parametrical studies accounting for different configurations and flow conditions and leading to in-depth understanding and innovative designs. Optimal GH conditions are attributed to several factors, including infiltrated solar irradiation, inlet flow conditions

${ }^{*}$ Corresponding author. Tel.: +971 28109130

Fax: +971 2810 9109; E-mail: isam.janajreh@ku.ac.ae

(C) 2018 International Association for Sharing Knowledge and Sustainability

DOI: $10.5383 /$ ijtee.17.01.002 (velocity, temperature, and relative humidity), and ratio of the transpiration plant area to the dry soil area. The abundant irradiation which infiltrates through the transparent GH walls provides photosynthetic energy in conjunction with the sensible and latent heat of evaporation that can integrated to the desalination of brine or brackish irrigation water source or as energy storage. The circulated air, the $\mathrm{CO}_{2}$ and $\mathrm{H}_{2} \mathrm{O}$ represent the main elements for plant growth; a moderate surrounding velocity is essential to maintain the healthy state of the plants and to provide the stipulated heating and cooling load; temperate relative humidity is necessary and should not be neither low to stress the plant transpiration nor high to promote the growth of algae and bacteria. Adrich and Bartok [5] indicated a stipulated comfortable range of the $\mathrm{GH}$ parameters for the temperature (10$\left.30^{\circ} \mathrm{C}\right)$, the relative humidity $(25-80 \%)$, and flow velocity $(0.1-$ $0.5 \mathrm{~m} / \mathrm{s})$.

Flow field simulation is pursued to provide the "knowhow" of the micro-climate condition distribution and for further control and manipulation in achieving optimal GH operation. Previous work has been carried out by Boulard et al [6] who studied the stratified and ventilated GH air flow pattern. Relying on flow in a porous media, that representing the bulk of the plant, they illustrated the mechanism of the near wall convection and the 
role it plays in stratifying the flow into the upper GH section and the outflow region. Lee and Short [7] studied the function of the tall crops on airflow, who also adapted a porous media flow, and inferred their mechanism for development of self-sustained GH. European Committee have also sponsored similar projects like Euro-Mediterranean Partnership undertaking GH numerical simulation demonstrating the implementation of $\mathrm{GH}$ in remote areas and communities subjected to water shortage [8]. Bartzanas et al [9] investigated the role of the screened tunnel type (insect-proof) $\mathrm{GH}$ via numerical simulation. His finding suggested the large drop in the flow velocity associated with the inclusion of the screen resulted in a big increase in temperature along the GH tunnel. Other GH flow simulations are those conducted by Kacira et al [10] who successfully investigated the temperature and flow pattern in a multi-span and saw-tooth greenhouse for various roof and side vent configurations. The pressure distribution on the external side of the GH roof was also investigated by Reichrath and Davies [11], who successfully validated their simulation with experimental work conducted on a 52-span Venlo-type GH. The multi-physics of the problem encouraged Howell and Potts [12] to incorporate the radiation absorption characteristics of water vapor in the air supported with extensive experimental measurements.

Fath and Abdelrahman [13] have conducted a detailed numerical study of the micro-climatic conditions of the GH. Their work is based on Navier-Stokes, turbulent and steady-state coupled with energy and humidity concentration equation for the flow within the GH cavity and also incorporated porous media model for the plant within. Their results presented a hot day operation and demonstrated the viability of high fidelity modeling as a tool for GH design. They evaluated the velocity, temperature and relative humidity fields and showed that a judicious choice of inlet flow condition can assure comfort values for plant growth.

This work complements previous work for the authors by evaluating the effect of the dominant environmental parameters for the GH using computational fluid dynamics through FLUENT-14.0 [14]. As a case study, the weather in Masdar city (located in the eastern Arabian Peninsula near Abu Dhabi) is considered for the implementation of the $\mathrm{GH}$ and considering the diurnal variation. The Abu Dhabi climate is characterized as hot and humid with intense solar irradiation during summer and hot temperatures, while it is comfortably humid and near room conditions during winter time [15]. A parametric study is conducted by varying the inlet velocity, temperature, and the plants' trans-evaporative rate to observe their pronounce impact on the plant micro-condition detected by relative humidity spatial distributions.

\section{Baseline Configuration}

The GH baseline geometry is given in Figure 1. It consists of an inlet of mass flow (velocity and direction), an outlet (pressure and direction) wall boundaries (no slip and no penetration velocity) within the flow cavity. Highly humid air near saturation, according to psychrometric chart, enters the GH. As it enters, its temperature increases due to the heat gain inside the GH cavity, vis-à-vis solar irradiation, convective sensible heat as well as form of latent heat of evaporation from the plant. This leads to a reduction in the relative humidity and stratification towards the still region (It is isolated from the plants in this analysis). The high thermal energy fluid, along with the still received irradiation, can have multiple usage, i.e desalinate a considerable volume of a brine or a brackish/grey water storage in the form of sensible heat, or potential use for adsorption chiller cooling. When operating the combined greenhouse still, the lower outside temperature near the still promotes condensation of the evaporated fluid and is accumulated on the inclined surface of the GH following passively or actively collecting mechanism. The heat can be regenerated for the still heating during the absent of the irradiation processes particularly in the night time.

\section{Numerical Simulation}

\subsection{System of Equations}

The flow is governed by the three-dimensional, transient, incompressible, non-isothermal Navier-Stokes and energy equations along with the transport species for the water vapor. These equations represent statements of mass continuity, momentum conservation and energy conservation. They can be written after applying the scalar variable expansion $\emptyset \mathrm{i}(\overrightarrow{\mathrm{x}}, \mathrm{t})=$ $\bar{\emptyset} \bar{i}(\vec{x}, t)+\emptyset i^{\prime}(\vec{x}, t)$ and ensemble (overbar) averaging as:

Continuity: $\frac{\partial \bar{\rho}}{\partial t}+\frac{\partial \overline{\rho u_{i}}}{\partial x_{i}}=S_{c}$

Where $\rho$ is the density, $t$ is the time advancement, $x i$ is the Cartesian coordinate $(\mathrm{i}=1,2,3), u_{i}$ is the velocity component in $x_{i}$ direction, and $S_{c}$ is any mass source as in the case when water vapor generated by the plant transpiration.

Momentum: $\frac{\partial \overline{\rho u_{i}}}{\partial t}+\frac{\partial \rho \overline{u_{i}} \overline{u_{j}}}{\partial x_{j}}=\frac{\partial \tau_{i j}}{\partial x_{j}}+\bar{\rho} g_{i}+S_{i}$

Where $\tau_{i j}$ is the surface stress tensor comprised of the hydrostatic pressure and viscous stress. $S_{i}$ is the momentum source/sink term which also is comprised of two terms associated with the velocity as viscous losses and velocity square as inertial losses and appears for the porous or the plants region of the flow domain. The term $\rho g i$ is the gravitational acceleration component in $x_{i}$ direction which also constitutes to the buoyancy force and modeled following Boussinesq model $\rho^{\prime}=\rho\left[1-\beta\left(T-T_{\text {ref }}\right)\right]$ where $\beta$ is the thermal expansion defined as $\beta=\frac{1}{\rho}\left(\frac{\delta \rho}{\delta T}\right)$.

Constitutive: $\tau_{i j}=-\bar{p} \delta_{i j}+\mu\left(\frac{\partial \overline{\rho u_{i}}}{\partial x_{j}}+\frac{\partial \overline{\rho u_{j}}}{\partial x_{i}}\right)-\overline{\rho u_{i}^{\prime} u_{j}^{\prime}}$

where $\mu$ is the molecular viscosity, $u_{i}^{\prime}$ is the velocity fluctuation about ensemble average velocities. The $\overline{\rho u_{i}^{\prime} u_{j}^{\prime}}$ term is the Reynolds stresses and is modeled utilizing the mean $(\overline{\mathrm{u}})$ velocity via the robust eddy viscosity $\mathrm{k}-\in$ turbulent. It is expressed as:

$$
-\overline{\rho u_{i}^{\prime} u_{j}^{\prime}}=\mu_{t}\left(\frac{\partial \overline{\rho u_{i}}}{\partial x_{j}}+\frac{\partial \overline{\rho u_{j}}}{\partial x_{i}}\right)-\frac{2}{3} \bar{\rho} k \delta_{i j}
$$

where $k$ is the kinetic turbulent energy $\left(k=\overline{\mathrm{u}_{\mathrm{k}}^{\prime} \mathrm{u}_{\mathrm{k}}^{\prime}}\right)$ and $\mu_{t}$ is the turbulent viscosity which relates $k$ and the turbulent dissipation rate $\varepsilon$ such that:

$$
\mu_{t}=f_{\mu} \frac{C_{\mu} k^{2}}{\varepsilon}
$$

Where $\mathrm{f}_{\mu}$ and $\mathrm{C}_{\mu}$ are empirical constants. Substituting Eq. (4) in (3) conveniently allows summing the Reynolds stresses terms to 
the diffusion term (second right hand term in Eq. (3)) with an equivalent viscosity:

$$
\mu_{\text {equ }}=\mu+\mu_{\mathrm{t}}
$$

Therefore, closure of the above system is achieved with the integration of two additional transport equations for each of $\mathrm{k}$ and $\varepsilon[31]$

Energy Equation has the following form:

$$
\frac{\partial}{\partial x_{i}}\left[u_{i}(\rho e+p)\right]=\frac{\partial}{\partial x_{i}}\left[\left(K+\frac{c_{p} \mu_{t}}{\operatorname{Pr}_{t}}\right) \frac{\partial T}{\partial x_{i}}-\sum_{j} h_{j} J_{j}\right]+S_{h}
$$

where $e$ is the total fluid energy $\left(e=\sum_{j} h_{j} Y_{j}+u^{2} / 2\right), h$ is the sensible enthalpy which is defined for the $\mathrm{j}$ species with a mass fraction $\mathrm{Yj}$ as $h_{j=} \int_{\mathrm{T}_{\mathrm{ref}}}^{\mathrm{T}} \mathrm{C}_{\mathrm{p}, \mathrm{j}} \mathrm{dT} . \mathrm{K}$ here is the thermal conductivity, $\mathrm{C}_{\mathrm{p}}$ is the constant pressure specific heat, and Prt is the Prandtl number which is the ratio of the turbulent kinematic viscosity to thermal diffusivity $\left(\operatorname{Prt}=\mathrm{C}_{\mathrm{p}} \mu_{t} / \mathrm{K}\right)$. Note that the conductivity in the energy equation (7) is a combined quantity, i.e. $K=\gamma \mathrm{K}_{\mathrm{f}}+(1-\gamma) \mathrm{K}_{\mathrm{S}}$ where $\mathrm{K}_{\mathrm{f}}$ and $\mathrm{K}_{\mathrm{s}}$ are referred to the fluid and solid thermal conductivity, respectively and $\gamma$ is the material fraction.

As the flow has the water vapor specie additional to the air, its transport equation is also included which is described as follows:

$$
\left.\frac{\partial}{\partial x_{i}}\left[\rho \phi u_{i}\right)\right]=\frac{\partial}{\partial x_{i}}\left(\Gamma \frac{\partial \phi}{\partial x_{i}}\right)+S_{\phi}
$$

where $\emptyset$ is any of the scalar property including (turbulence quantities $\mathrm{k}$ and $\epsilon$ as well as the species concentration $\mathrm{Y}$ ) and thus the transport equation for the Water vapor fraction can be written as:

$$
\left.\frac{\partial}{\partial x_{i}}\left[\rho Y_{\mathrm{H}_{2} \mathrm{O}} u_{i}\right)\right]=\frac{\partial}{\partial x_{i}}\left(\rho D_{\mathrm{H}_{2} \mathrm{O}}+\frac{\mu_{t}}{S c_{t}}\right) \frac{\partial Y_{\mathrm{H}_{2} \mathrm{O}}}{\partial x_{i}}+S_{\mathrm{H}_{2} \mathrm{O}}
$$

Where the $\mathrm{D}_{\mathrm{H} 2 \mathrm{O}}$ and $\mathrm{Sc}$ are the water vapor-air diffusion coefficient and turbulent Schmidt numbers which they take the common values of $2.88 \mathrm{E}-5$ and 0.7 , respectively.

The flow in porous media is governed by the same equations incorporating the porosity $(\gamma)$ multiplication in equation (8), where $\gamma$ of the media is defined as the void to the total volume ratio. The momentum equation also includes an empirically determined flow resistance $\left(S_{i}\right.$ in the governing momentum equations) which mathematically is written as:

$$
S_{i}=-\left(\sum_{j=1}^{3} D_{i j} \mu v_{j}+\sum_{j=1}^{3} C_{i j} \frac{1}{2} \rho v_{m a g} v_{j}\right)
$$

This term is comprised of two parts: a viscous loss term, and an inertial loss term where $\nu_{\text {mag }}$ is the velocity magnitude and $\mathrm{D}$ and $\mathrm{C}$ are prescribed matrices. This momentum sink affects the pressure gradient in the porous cell and creates a pressure drop proportional to the fluid velocity (or velocity squared) in the cell. In the case of simple homogenous porous media, the equation (10) reduces to:

$$
\mathrm{S}_{\mathrm{i}}=-\left(\frac{\mu}{\alpha} v_{\mathrm{i}}+\mathrm{C}_{2} \frac{1}{2} \rho v_{\operatorname{mag}} v_{\mathrm{i}}\right)
$$

Where $\alpha$ is the permeability and $\mathrm{C}_{2}$ is the inertial resistance factor. In fluent, D and $\mathrm{C}$ are specified as diagonal matrices with $1 / \alpha$ and $C_{2}$, respectively. In the current analysis a well grown tomato crop is represented by $50 \%$ porosity, and with a permeability value $(\propto)$ of 0.395 and inertia resistance value $\left(C_{2}\right)$ of $1.6[4]$.

\subsection{Discretization and Boundary Conditions}

The geometry given in Figure 1 was discretized using quad mesh type. The admitted kinematic and thermal boundary and species conditions as summarized in Table 1. Three types of flow regions are considered: main flow region, the porous plants/crops region, and the still region. The crops region is bounded by the ground and placed in the middle of the GH. It is modeled as a porous media at $50 \%$ permeability and specified values of viscous resistance of $2.53164 \mathrm{~m}^{-2}$ and inertial resistance of $1.6 \mathrm{~m}^{-1}$. It is also subjected to osmotic source moisture and heat sink as water transported from the soil through the roots and evaporated from the plant's leaf's in the form of latent heat of evaporation. The still is subjected to evaporation that occurs at the bottom surface and condensation at the top surface, which are accounted for and modeled via a replenishing moisture source of an equal value to moisture sink at the still top, respectively. To capture the temperature gradient and the viscous boundary layer, the standard wall function next to the walls is implemented and a normalized wall distance

\begin{tabular}{|c|c|c|c|}
\hline Region & Kinematic & Thermal & Species $Y_{\mathrm{H} 2 \mathrm{O}}$ \\
\hline A & $\begin{array}{l}\text { No slip } \\
\text { wall }\end{array}$ & $308 \mathrm{~K}^{\mathrm{o}}$ & $\frac{\partial Y_{H 2 O}}{\partial x}=0$ \\
\hline B & $\begin{array}{l}\text { No slip } \\
\text { wall }\end{array}$ & $313 \mathrm{~K}^{\mathrm{o}}$ & $-0.1 \mathrm{~g} / \mathrm{s} . \mathrm{m}^{2}$ \\
\hline $\mathrm{C}$ & $\begin{array}{l}\text { No slip } \\
\text { wall }\end{array}$ & $308 \mathrm{~K}^{\mathrm{o}}$ & $\frac{\partial Y_{H 2 O}}{\partial x}=0$ \\
\hline $\mathrm{D}$ & $\begin{array}{l}\text { No slip } \\
\text { wall }\end{array}$ & $\begin{array}{l}\frac{\partial T}{\partial y}=0 \text { (zero } \\
\text { flux) }\end{array}$ & $\frac{\partial Y_{H 2 O}}{\partial y}=0$ \\
\hline $\mathrm{E}$ & $\begin{array}{l}\text { No slip } \\
\text { wall }\end{array}$ & $303 \mathrm{~K}^{\mathrm{o}}$ & $\frac{\partial Y_{H 2 O}}{\partial x}=0$ \\
\hline F (Inlet Flow) & $\begin{array}{l}\mathrm{u}=0.5 \mathrm{~m} / \mathrm{s}, \\
\mathrm{v}=0, \\
\mathrm{k}=1 \mathrm{~m}^{2} / \mathrm{s}^{2}, \\
\varepsilon=1 \mathrm{~m}^{2} / \mathrm{s}^{3}\end{array}$ & $298 \mathrm{~K}^{\mathrm{o}}$ & $\begin{array}{l}0.015 \\
\mathrm{~kg}\left(\mathrm{H}_{2} \mathrm{O}\right) / \mathrm{kg} \text { Air }\end{array}$ \\
\hline G & $\begin{array}{l}\text { No slip } \\
\text { wall }\end{array}$ & $303 \mathrm{~K}^{\mathrm{o}}$ & $\frac{\partial Y_{H 2 O}}{\partial x}=0$ \\
\hline $\mathrm{H}$ & $\begin{array}{l}\text { No slip } \\
\text { wall } \\
\partial v\end{array}$ & $308 \mathrm{~K}^{\mathrm{o}}$ & $\frac{\partial Y_{H 2 O}}{\partial x}=0$ \\
\hline I (Outlet Flow) & $\begin{array}{l}\frac{\partial y}{\partial y}=0 \\
\frac{\partial u}{\partial x}=0\end{array}$ & $\frac{\partial T}{\partial y}=0$ & $\frac{\partial Y_{H 2 O}}{\partial y}=0$ \\
\hline $\mathrm{J}$ & $\begin{array}{l}\text { No slip } \\
\text { wall }\end{array}$ & $328 \mathrm{~K}^{\mathrm{o}}$ & $0.1 \mathrm{~g} / \mathrm{s} . \mathrm{m}^{2}$ \\
\hline K & $\begin{array}{l}\text { No slip } \\
\text { wall }\end{array}$ & $\begin{array}{l}\text { Interior and } \\
\text { coupled via } \\
\text { conduction }\end{array}$ & $\frac{\partial Y_{H 2 O}}{\partial y}=0$ \\
\hline $\mathrm{L}$ & $\begin{array}{l}\text { No slip } \\
\text { wall }\end{array}$ & $\begin{array}{l}\text { Interior and } \\
\text { coupled via } \\
\text { conduction }\end{array}$ & $\frac{\partial Y_{H 2 O}}{\partial x}=0$ \\
\hline
\end{tabular}
$\left(\mathrm{y}+=\mathrm{u}_{\mathrm{w}} \rho \mathrm{u} / \mu\right)$ of 30 is targeted corresponding to the mean entry flow velocity. This achieved iteratively following three refinement levels for the mesh where results of the flow at critical sections are compared.

Table 1. Summary of baseline GH flow boundary conditions 


\subsection{Mesh Sensitivity Study}

Sensitivity analysis for maximum velocity and temperature at the middle of the GH was carried out on three levels of mesh refinements, fine, intermediate and coarse mesh. The number of cells of the two-successive coarse meshes is at $1 / 8$ th and $1 / 16$ th number of elements. Result are tabulated below, in Table 2, along the vertical line segment that stretch from $(3 \mathrm{~m}, 0)$ to $(3 \mathrm{~m}$, $3.5 \mathrm{~m})$. The intermediate mesh is used for the subsequent analysis.

\section{Results and Discussion}

The simulation model has many outputs comprising system performance and parameters. For the present purpose, outputs that have direct and practical implications are emphasized: velocity vector inside the greenhouse-distiller, contours of stream function, contours of temperature field, and contours of relative humidity, as well as mass fraction distribution. Figure 2 shows the velocity vectors and contours of stream function. It shows the flow pattern within the GH and the roof distiller. The velocity vector shows the maximum velocity of $2 \mathrm{~m} / \mathrm{s}$ near the exit. The velocity within the plant zone is between $0.025 \mathrm{~m} / \mathrm{s}$ to $0.225 \mathrm{~m} / \mathrm{s}$ and falls within the acceptable limit for plant growth. The stream function shows the trajectory of particles in steady state flow. It is evident from the stream function that there is high flow circulation just above to the flow inlet. The recirculation can cause a potential obstruction to the incoming flow to the extent of causing or choking the flow. Also, the sharp transition within the GH resulted in flow separation.

Figure 3 shows the temperature contours within the greenhousestill system. The temperature distribution within the plant cavity shows that temperature values comply with the plant growth requirement. The maximum temperature is near the roof region. The roof still flow pattern, as shown by the flow stream function, velocity vectors and temperature contours, show free convention as the only driving force for natural flow circulation within the still in the absent of radiation integration. In the roof hot air rises upwards and cold air flows head downwards. In this analysis the roof/still is isolated form rest of the greenhouse cavity but is coupled by the imposed temperature value at the bottom and along the ventilation chimney.

Figure 4 shows the relative humidity contours within the greenhouse-still system. The relative humidity within the plant zone is between $40-43 \%$ which is below the optimal comfort value that can be improved via increase the incoming moisture (relative humidity) or by increase of the transpiration of the plant (a source within the porous zone).

Figure 5 shows the contours of the mass fraction of water inside the greenhouse cavity. The figure shows the increase of water mass fraction inside the plant zone in the stream-wise direction due to water vapor generation inside the plant zone.
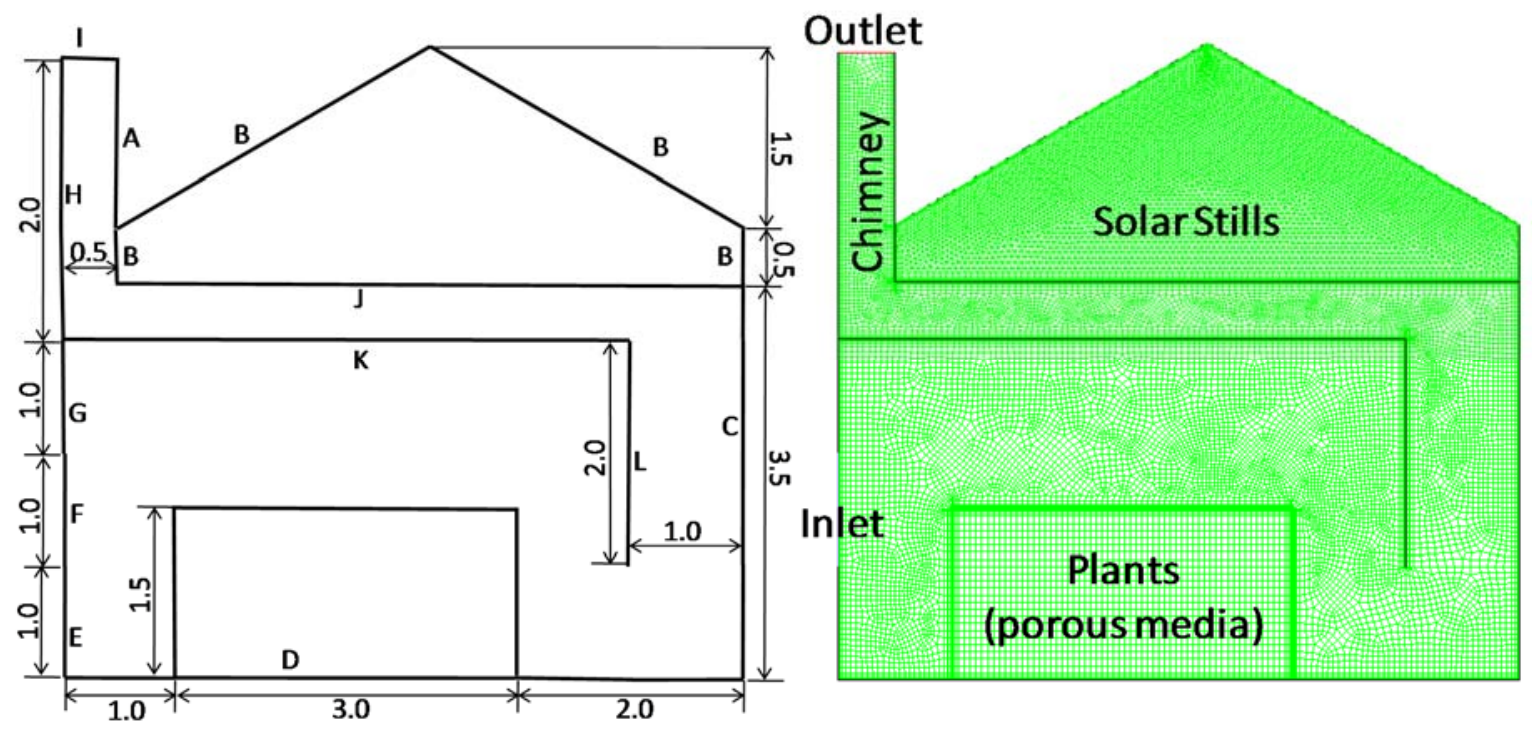

Fig. 1. GH Baseline geometry showing the different boundary region and flow conditions

Table 2. Mesh sensitivity analysis

\begin{tabular}{ccccccccc}
\hline & \multicolumn{2}{c}{ Velocity magnitude $(\mathrm{m} / \mathrm{s})$} & \multicolumn{2}{c}{ Error } & \multicolumn{2}{c}{ Static temperature $(\mathrm{K})$} & \multicolumn{2}{c}{ Error } \\
\cline { 2 - 9 } Mass average & $\mathrm{Y}$ & $\mathrm{Y}$ & $\mathrm{Y}$ & $\mathrm{Y}$ & $\mathrm{Y}$ & $\mathrm{Y}$ & $\mathrm{Y}$ & $\mathrm{Y}$ \\
\cline { 2 - 9 } & $0-3$ & $3-3.5$ & $0-3$ & $3-3.5$ & $0-3$ & $3-3.5$ & $0-3$ & $3-3.5$ \\
\hline Fine & 0.225735 & 0.197686 & & & 319.167 & 328 & & \\
\hline Intermediate & 0.298963 & 0.713653 & 0.099202 & 0.515967 & 319.279 & 328 & 0.112 & 0 \\
\hline Coarse & 0.540357 & 0.907061 & 0.340596 & 0.709375 & 319.277 & 328 & 0.11 & 0 \\
\hline
\end{tabular}


Raza et al. / Int. J. of Thermal \& Environmental Engineering, 18 (2018) 11-18

(a)

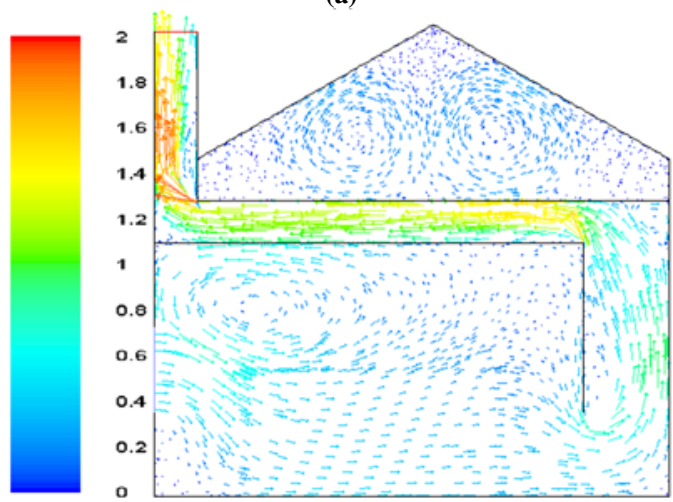

(b)

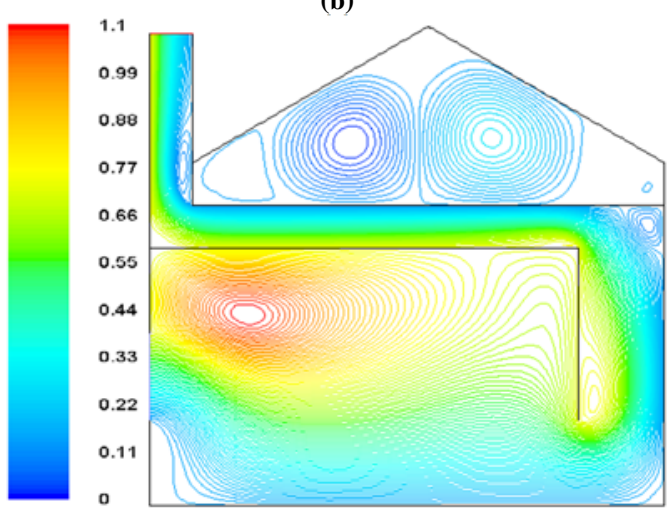

Fig. 2. (a) Contours of velocity vectors (m/s), and (b) contours of stream function ( $\mathrm{kg} / \mathrm{s})$
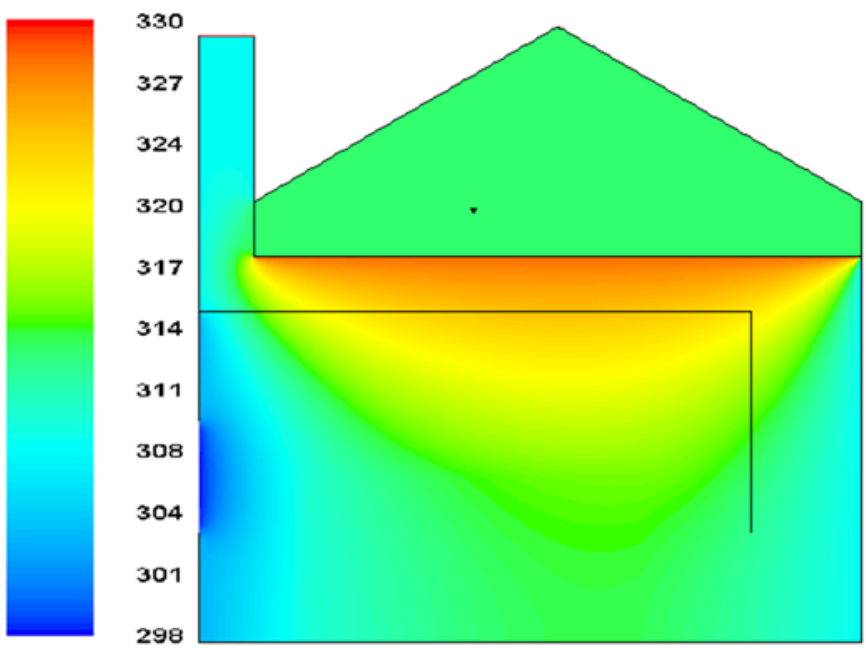

Fig. 3. Contours of temperature (K)
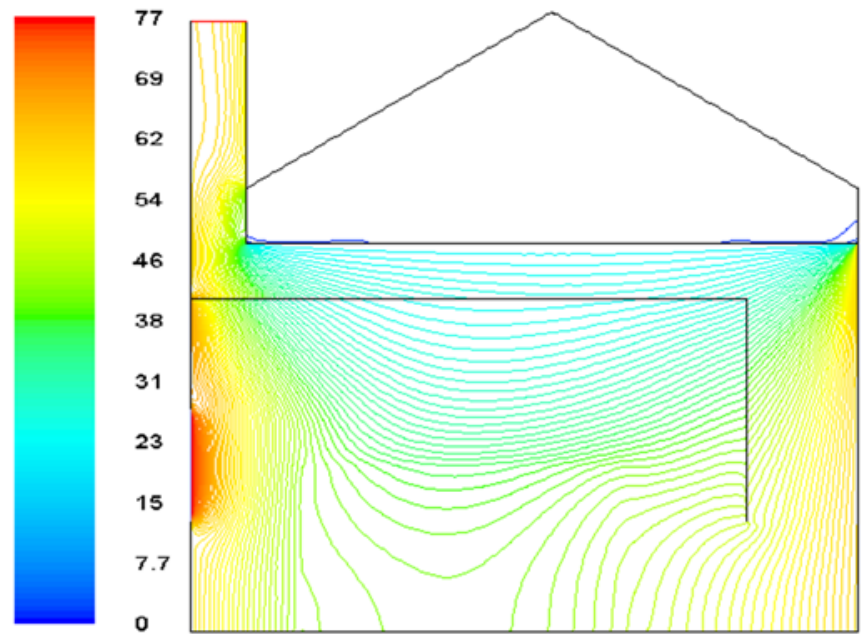

Fig. 4. Contour of relative humidity 

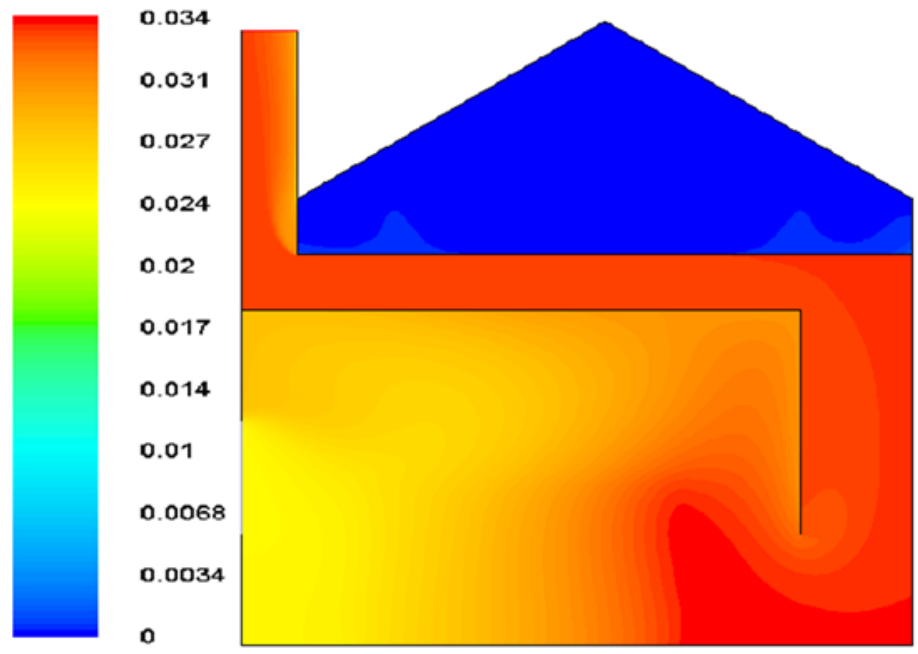

Fig. 5. Contour of water mass fraction

\section{Parametric Study}

In this study, variation of incoming temperature, velocity and transpiration plant rates have been considered to observe their effect on the overall microclimate condition of the GH. The relative humidity is presented along the vertical line downstream of the porous plants at $\mathrm{x}=5 \mathrm{~m}$. Results are presented as a line plot as depicted in Figures 6 through 8. Results show that diurnal variation in the inlet temperature (up to $10 \mathrm{C}^{\circ}$ ) seems to have a slight effect on the spatial relative humidity. The effect, however, preserves the inverse proportionality trend that is higher temperatures result in lower humidity. The influence of the velocity is more pronounced within a range of values that can be observed in the same day, e.g. high velocity resulted in lower relative humidity. It is due to the fact that incoming flow represents the source of this humidity and lower velocity signifies longer residence time and thus a higher moisture accumulation and relative humidity. Lastly, the influence of the transpiration rate of the plant on relative humidity has another pronouncing effect and with a range of values that can replicate transpiration of the plant or on conjunction with the soil transpiration during irrigation intervals. The relative humidity is directly proportional to the evaporated amount. The average values of the relative humidity inside and outside the plant zone are summarized in Table 3 . These values replicate the previously observed trends but more quantitatively. As temperature increase by $8 \mathrm{C}^{\circ}$ the relative humidity decreases with few percentiles $(\sim 2 \%)$. When velocity varies between $0.2-0.7 \mathrm{~m} / \mathrm{s}$, and within the diurnal operation of the $\mathrm{GH}$, an increase up to 5 points in the humidity is observed. Finally, when the transpiration increased from 0.2 to $1.2 \mathrm{~g} / \mathrm{m}^{3}$ the relative humidity observes a drastic jump of over 15 points. Further work is indeed needed to assess the manipulation temperature inside the greenhouse, among those is cooling-tower integration in dry or wet depending on the material, attained conditions, and thermal properties. This opens a wide door of research on how to build and operate a sustainable greenhouse as far as water, thermal energy management, and renewable energy integration to reduce production or crops yield cost as well as their environmental footprint.

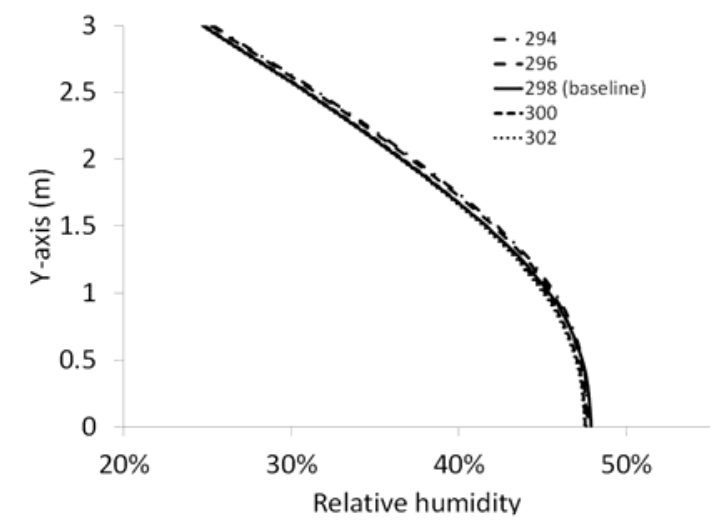

Fig. 6. Influence of inlet temperature on the relative humidity along the $\mathrm{GH}$ vertical line

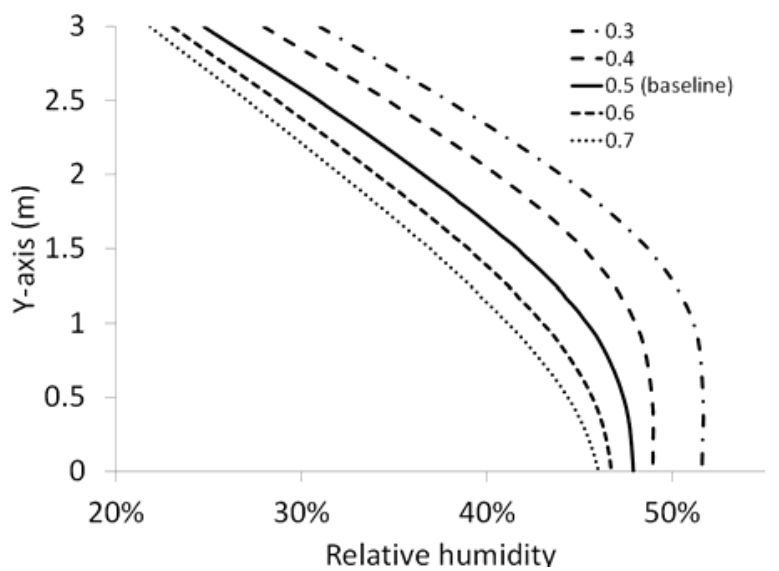

Fig. 7. Influence of inlet velocity on the relative humidity along the GH vertical line 


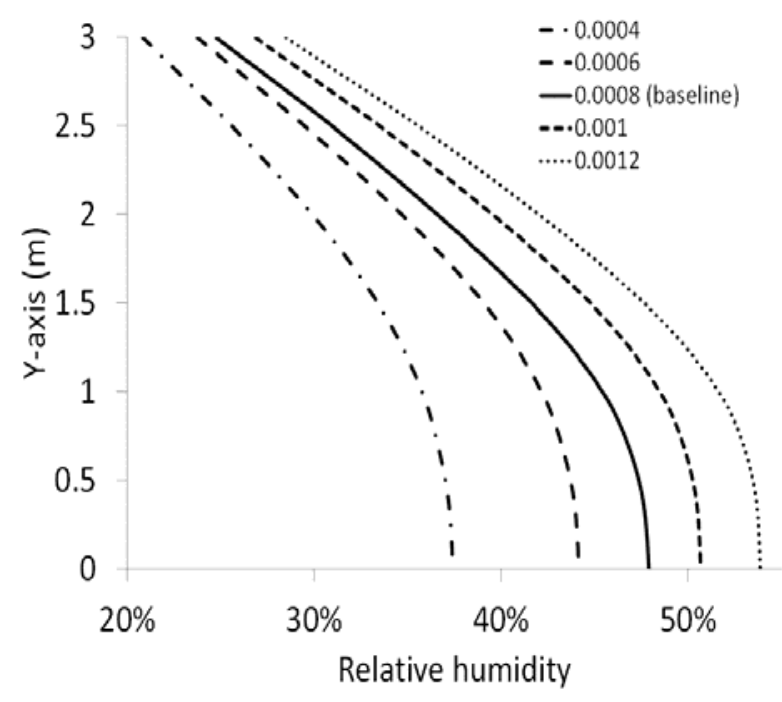

Fig. 8. Influence of transpiration rate on the relative humidity along the $\mathrm{GH}$ vertical line

\section{Conclusions}

To gain a further fundamental understanding of the microclimate condition with the GH, Numerical simulation based on Navierstokes turbulent multiple species (air and moisture) steady flow was carried out. The results for velocity vector, temperature and humidity are presented within the GH cavity which shows substantial local variation. FLUENT 6.3.26 was used to solve two-dimensional fully turbulent, non-isothermal, incompressible flow. The choice and control of an appropriate inflow boundary condition will lead to velocity and temperature within the acceptable limit (comfort zone) for plant growth. A Sensitivity study was further carried out considering the diurnal velocity variation, rate of plant transpiration, and inlet temperature. The velocity and transpiration have a more pronounced effect on the relative humidity than on the temperature variation. In particular as temperature increases by $8 \mathrm{C}^{\circ}$ the relative humidity decreases by a few percentiles $(\sim 2 \%)$. When velocity varies between $0.2-0.7 \mathrm{~m} / \mathrm{s}$, and within the diurnal operation of the GH, an increase of up to 5 points in the humidity is observed. Finally, when the transpiration increased from 0.2 to $1.2 \mathrm{~g} / \mathrm{m}^{3}$ the relative humidity observed a drastic jump of over 15 points.

Table 3. Summary of the inlet temperature and velocity as well as transpiration plant rate on the microclimate condition of the GH

\begin{tabular}{|c|c|c|c|c|c|}
\hline \multirow{2}{*}{$\begin{array}{l}\text { Influence of Temperature } \\
\text { Inlet temperature }(\mathrm{K})\end{array}$} & \multicolumn{5}{|c|}{ baseline } \\
\hline & 294 & 296 & 298 & 300 & 302 \\
\hline Average temperature $(\mathrm{K})$ & 314.8243 & 314.9758 & 315.1273 & 315.2788 & 315.4303 \\
\hline Average relative humidity (\%) & 41.0216 & 40.59344 & 40.00701 & 39.78392 & 39.42106 \\
\hline$R H$ inside porous media & 42.37916 & 41.78882 & 41.2159 & 40.6677 & 40.13627 \\
\hline Influence of Velocity & \multicolumn{5}{|c|}{ baseline } \\
\hline Inlet velocity $(\mathrm{m} / \mathrm{s})$ & 0.3 & 0.4 & 0.5 & 0.6 & 0.7 \\
\hline Average temperature $(\mathrm{K})$ & 315.1273 & 315.1273 & 315.1273 & 315.1273 & 315.1273 \\
\hline Average relative humidity (\%) & 46.5119 & 42.85469 & 40.00701 & 38.39698 & 37.1961 \\
\hline$R H$ inside porous media & 46.78777 & 43.14297 & 41.2159 & 40.25149 & 39.68393 \\
\hline Influence of Transpiration & \multicolumn{5}{|c|}{ baseline } \\
\hline Porous source term $\left(\mathrm{Kg} / \mathrm{m}^{3}-\mathrm{s}\right)$ & 0.0004 & 0.0006 & 0.0008 & 0.001 & 0.0012 \\
\hline Average temperature $(\mathrm{K})$ & 315.1273 & 315.1273 & 315.1273 & 315.1273 & 315.1273 \\
\hline Average relative humidity (\%) & 33.75333 & 38.09028 & 40.00701 & 42.50428 & 44.72263 \\
\hline RH inside porous media & 35.72076 & 39.39691 & 41.2159 & 43.08527 & 44.92501 \\
\hline
\end{tabular}




\section{Acknowledgments}

The support received from Masdar Institute and Masdar Initiative to carry out this work is highly acknowledged.

\section{References}

[1] M.A.S. Malik, G.N. Tiwari, A. Kumar and M.S. Sodha, Solar Distillation, Pergamon Press, New York, 1982.

[2] H.E.S. Fath, Development of a natural draft solar fan ventilation of greenhouses in hot climates, Int. J. Solar Energy, 13 (1993) 237-248.

[3] H.E.S. Fath, Transient analysis of naturally ventilated greenhouse with built-in solar still and waste heat and mass recovery system, Energy Convers. Mgmt., 35(11) 1994, pp. 955-965.

[4] H.E.S. Fath, An integrated agriculture system: a self sufficient of energy and irrigating water, Proc. Third Gulf Water Conference, Muscat, Oman, 1997.

[5] A.R. Aldrich and J.W. Bartok, Greenhouse Engineering, The Northeast Regional Agricultural Engineering Services, 1990

[6] T. Boulard, R. Haxaire, M.A. Lamrani, J.C. Roy and A. Jaffrin, Characterization and modelling of the air fluxes indicated by natural ventilation in a greenhouse, J. Agrc. Engng. Res., 74 (1999) 135-144.

[7] I. Lee and T.H. Short, Two-dimensional numerical simulation of natural ventilation in a multi-span greenhouse, Trans. ASME, 43(2) (2000) 745-753.
[8] Euro-Mediterranean Partnership, Autonomous desalination system concepts for sea water and brackish water in rural areas with renewable energies -potentials, technologies, field experience, sociotechnical and socioeconomic impact, ADIRA Project No. ME8/AIDCO/2001/0515/59610.

[9] T. Bartzana, T. Boulard and C. Kittas, Numerical simulation of the airflow and temperature distribution in a tunnel greenhouse equipped with insect-proof screen in the opening, Comp. Elec. Agrc., 34(1-3) (2002) 207-221

[10] M. Kaeira, T.H. Short and R.R. Stowell, A CFD evaluation of naturally ventilated, multi-span, sawtooth greenhouse, Trans. ASME, 41(3) (1998) 833.-836.

[11] S. Reichrath and T.W. Davies, Using CFD to model the internal climate of greenhouses: past, present, and future, Agronomic, 22 (2001) 3-9.

[12] S.A. Howell and I. Ports, On the natural displacement flow through a full-scale enclosure, and the importance of the radiative participation of the water vapor content of the ambient air, Building Environ., 37 (2002) 817-823.

[13] H. Fath, K. Abdelrahman, Micro-Climatic environmental conditions inside a greenhouse with a built-in solar distillation system, Desalination Vol. 171 (2004) pp.267-287.

[14] User's Guide, FLUENT 6.3, 2000.

[15] MN. Khan, I. Janajreh, Transevaporative Cooling Performance of a Three-Sided Wind Catcher. Jordan Journal of Mechanical \& Industrial Engineering. 2017 Dec 2;11(4). 